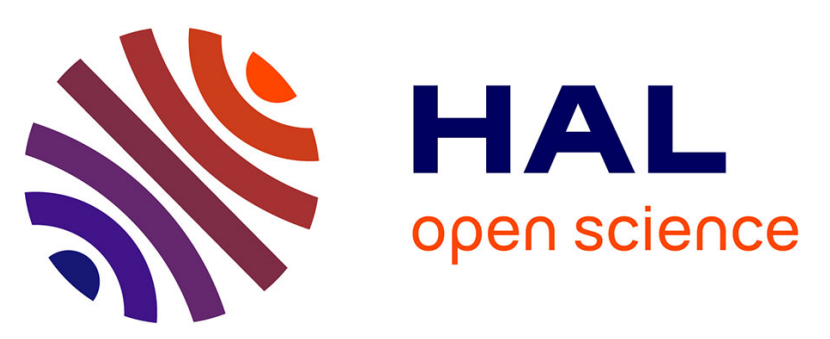

\title{
Low level exercise echocardiography helps diagnose early stage heart failure with preserved ejection fraction: a study of echocardiography versus catheterization
}

\author{
Nadjib Hammoudi, Florent Laveau, Gérard Helft, Nathalie Cozic, Olivier
}

Barthelemy, Alexandre Ceccaldi, Thibaut Petroni, Emmanuel Berman, Michel

Michel, Pierre-Louis Michel, et al.

\section{To cite this version:}

Nadjib Hammoudi, Florent Laveau, Gérard Helft, Nathalie Cozic, Olivier Barthelemy, et al.. Low level exercise echocardiography helps diagnose early stage heart failure with preserved ejection fraction: a study of echocardiography versus catheterization. Clinical Research in Cardiology, 2016, pp.1-10. 10.1007/s00392-016-1039-0 . hal-01377207

\section{HAL Id: hal-01377207 \\ https://hal.sorbonne-universite.fr/hal-01377207}

Submitted on 6 Oct 2016

HAL is a multi-disciplinary open access archive for the deposit and dissemination of scientific research documents, whether they are published or not. The documents may come from teaching and research institutions in France or abroad, or from public or private research centers.
L'archive ouverte pluridisciplinaire HAL, est destinée au dépôt et à la diffusion de documents scientifiques de niveau recherche, publiés ou non, émanant des établissements d'enseignement et de recherche français ou étrangers, des laboratoires publics ou privés. 


\title{
Low level exercise echocardiography helps diagnose early stage heart failure with preserved ejection fraction: a study of echocardiography versus catheterization
}

\author{
Nadjib Hammoudi, MD; \\ Florent Laveau, $\mathrm{MD}^{\mathrm{a}}$; Gérard Helft, MD, $\mathrm{PhD}^{\mathrm{a}}$; Nathalie Cozic ${ }^{\mathrm{b}}$; Olivier Barthelemy, $\mathrm{MD}^{\mathrm{a}}$; \\ Alexandre Ceccaldi ${ }^{\mathrm{a}}$, MD; Thibaut Petroni, MD ${ }^{\mathrm{a}}$; Emmanuel Berman ${ }^{\mathrm{a}}$; Michel Komajda, MD ${ }^{\mathrm{a}}$; \\ Pierre-Louis Michel, $\mathrm{MD}^{\mathrm{a}}$; Alain Mallet MD, $\mathrm{PhD}^{\mathrm{b}}$; Claude Le Feuvre, $\mathrm{MD}^{\mathrm{a}}$; Richard Isnard, MD \\ ${ }^{\text {a }}$ Université Paris 6, Institut de Cardiologie (AP-HP), Centre Hospitalier Universitaire Pitié-Salpêtrière, Institute \\ of Cardiometabolism and Nutrition (ICAN), INSERM UMRS 1166, Paris, France, ACTION Study Group. \\ ${ }^{\mathrm{b}}$ Université Paris 6, Département de Biostatistiques, Centre Hospitalier Universitaire Pitié-Salpêtrière, Paris, \\ France.
}

\section{Address for correspondence}

Nadjib Hammoudi, Institut de Cardiologie, Groupe Hospitalier Pitié-Salpêtrière, AP-HP, 47-83, boulevard de l'Hôpital, 75651 Paris Cedex 13. E-mail: nadjib.hammoudi@psl.aphp.fr. Telephone number: +33142165535 . Fax number: +33142163020 .

\section{Acknowledgements}

We thank Anissa Bouzamondo, Anne-Claire Coyne and Justine Pollet (French Society of Cardiology) for logistical and data-managing support as well as Sylvie Lang for careful review of the manuscript.

\section{Funding}

This work was supported by the French Federation of Cardiology and the French Society of Cardiology. 


\section{ABSTRACT}

Background: Increased left ventricular end diastolic pressure (LVEDP) with exercise is an early sign of heart failure with preserved left ventricular ejection fraction (LVEF). The abnormal exercise increase in LVEDP is nonlinear, with most change occurring at low-level exercise. Data on noninvasive approach of this condition are scarce. Our objective was assessing E/e' to estimate low level exercise LVEDP using a direct invasive measurement as the reference method.

Methods and Results: Sixty patients with LVEF $>50 \%$ prospectively underwent exercise cardiac catheterization and echocardiography. E/e' was measured at rest and during low-level exercise. Abnormal LVEDP was defined as $>16 \mathrm{mmHg}$. Patients with a history of coronary artery disease and/or abnormal LV morphology were classified as having apparent cardiac disease $(\mathrm{CD})$.

Thirty-four (57\%) patients had elevated LVEDP only during exercise. Most of the change in LVEDP occurred since the first exercise level (25Watts). There was a correlation between LVEDP and septal E/e' at rest and during exercise. Lateral E/e' and E/average e' ratio had worse correlations with LVEDP. In the whole population, exercise septal E/e' at 25 Watts had the best accuracy for abnormal exercise LVEDP, area under curve (AUC)=0.79. However, while low-level exercise septal E/e' had a high accuracy in CD patients ( $\mathrm{n}=26, \mathrm{AUC}=0.96)$, E/e' was not linked to LVEDP in patients without CD $(n=34)$.

Conclusion: Low-level exercise septal E/e' is valuable for predicting abnormal exercise LVEDP in patients with preserved LVEF and apparent CD. However, this new diagnosis approach appears not reliable in patients with normal LV morphology and without coronary artery disease.

Clinical Trial Registration: URL: https://clinicaltrials.gov. Unique identifier: NCT01714752 Key words: exercise; hemodynamics; echocardiography; heart failure 


\section{INTRODUCTION}

Heart failure $(\mathrm{HF})$ with preserved ejection fraction $(\mathrm{pEF})$ is increasing in prevalence and is becoming the predominant form of HF.[1-3] While cardiac dysfunction is readily apparent when the left ventricular ejection fraction (LVEF) is reduced,[4] the diagnosis of HFpEF is often not straightforward,[5] particularly in the early stages of the disease.[6] Identifying HFpEF at an early stage, when the structural changes in the heart and vasculature are still reversible, may be important for improving the prognosis of the disease.[7] Invasive hemodynamics have demonstrated relevance for the diagnosis of early stage of HFpEF, which is characterized by exercise-induced left ventricular filling pressure (LVFP) elevation despite normal resting pressures.[6]'[8] Interestingly, the abnormal exercise increase in LVFP is nonlinear, with most change occurring at low level exercise.[6]

Data on noninvasive approach of exercise LVFP more suitable for routine clinical use are scarce. The value of Doppler echocardiography using the ratio of early diastolic transmitral velocity to tissue velocity (E/e') for the noninvasive evaluation of LVFP has been reported.[9, 10] Nevertheless, there are limited and conflicting data on the validation of exercise E/e' with invasively determined LVFP in patients with preserved LVEF.[11, 12] Moreover, whereas latent heart failure could be unmasked during exercise in patients with apparently normal LV structure and function at rest, $[6,13] \mathrm{E} / \mathrm{e}^{\prime}$ was reported as less valuable in patients without evidence of cardiac disease (CD) at steady state.[14-16] Thus the clinical integration of exercise E/e' in daily clinical practice is debated.[17-19]

The aim of this study was to assess the E/e' ratio for the estimation of low level exercise LVFP using a direct invasive measurement as the reference method in patients at high risk of HFpEF. 


\section{METHODS}

\section{Ethics statement}

This study was carried out in accordance with the Helsinki Declaration and was approved by the local institutional committee on human research. Written informed consent was obtained from each patient before participation.

\section{Patient population}

We prospectively enrolled 60 patients in sinus rhythm with LVEF $>50 \%$ and undergoing clinically indicated left heart catheterization using a transradial approach, which allowed for the invasive measurement of left ventricular end-diastolic pressure (LVEDP). The risk factors of coronary artery disease, especially age, hypertension and diabetes, are also recognized risk factors of HFpEF. Thus, the patients referred for coronary angiography are also at high risk of

\section{HFpEF.[2]}

Patients in whom the radial artery puncture was not feasible and those who were unable to pedal were excluded. The other exclusion criteria were more than mild mitral regurgitation, severe aortic stenosis, mitral stenosis, valvular prosthesis, severe mitral annular calcification, hypertrophic cardiomyopathy, heart transplantation, LV thrombus, severe renal failure $\left(<30 \mathrm{ml} / \mathrm{min} / 1.73 \mathrm{~m}^{2}\right)$, atrial fibrillation, an acute coronary syndrome in the previous 3 months and/or the diagnosis during coronary angiography of a stenosis requiring revascularization. The baseline evaluation comprised the collection of medical history, a physical examination, electrocardiogram and blood sampling for laboratory measurements including N-terminal probrain natriuretic peptide (NT-pro BNP).

Patients with apparent CD were defined as having either clinical history of coronary artery disease (prior myocardial infarction or prior coronary revascularization), coronary stenosis 
$>50 \%$ on coronary angiography or echocardiographic evidence of LV structural abnormality (hypertrophy or remodeling) as defined by the echocardiography guidelines.[15, 16, 20]

\section{Invasive hemodynamic assessment}

After coronary angiography, a fluid-filled pigtail catheter was positioned in the mid-LV cavity. Transducers were balanced before the study with the zero level at the mid-axillary line. LV pressure tracings were recorded at baseline and during exercise. Measurements were made off-line by two experienced physicians who were blinded to echocardiography and clinical data. LVEDP were averaged over five cardiac cycles, and ectopic or post-ectopic beats were disregarded. LVEDP $>16 \mathrm{mmHg}$ was used as a threshold to define abnormal LVFP at rest and during exercise.[21, 22]

\section{Echocardiographic studies}

Transthoracic echocardiography was performed in all patients using the Vivid 9 system. The images were transferred to a workstation equipped with the Echopac PC software (GE Vingmed; Horten, Norway). All the examinations were analyzed off-line by two senior cardiologists who were blinded to the clinical data and invasive measurements. All projections were obtained according to the guidelines.[20] All measurements were averaged over 3 to 6 cardiac cycles. Ectopic and post-ectopic beats were disregarded.

In M-mode, the following measurements were made at end diastole: LV internal diameter and inter-ventricular septal and posterior wall thicknesses. LV mass was derived and indexed to body surface area. Relative wall thickness was also calculated.[20]

From the 2-dimensional mode, the LA maximal volume was measured by the biplane Simpson method and was indexed to body surface area (LAVi). LV volumes and LVEF were measured using the biplane Simpson method.[20] From the continuous wave Doppler, peak tricuspid regurgitation was selected. 
From the pulsed wave Doppler mode positioned at the tip of the mitral valve, early (E) and late (A) peak diastolic velocities of the mitral inflow and E-wave deceleration time were measured. The septal, lateral and average early diastolic velocities were recorded (e'), and the ratio of mitral flow E to e' for each of these annular velocities was calculated.[16, 23] In addition to steady state measures, the E and e' wave velocities were recorded, and the different $\mathrm{E} / \mathrm{e}$ ' ratios were calculated during exercise. In cases of complete merging of $\mathrm{E}$ and $\mathrm{A}$ for the mitral inflow, peak E was measured at the peak of the single wave form. With complete merging of $\mathrm{e}^{\prime}$ and a', the resulting velocity was taken as $\mathrm{e}^{\prime}$.[24]

\section{Exercise protocol}

A similar two leg pedaling exercise was performed within 24 hours in the catheterization laboratory using ERG 911 BP/XRAY and in the echocardiography laboratory using ERG 911 L/LS (Schiller, Switzerland). Patients in the supine position pedaled at a constant speed beginning at a workload of 25 Watts for 3 minutes, followed by a workload of 50 Watts for an additional 3 minutes. Invasive and non-invasive data were stored at baseline and during the last minute of both levels of exercise. Relatively low levels of exercise were chosen because obviously all the patients can reach this threshold,[25] and invasive LV pressure tracings, as well as echocardiographic image quality, are well maintained at this workload.[19, 26] Moreover, most of the changes in LVFP occur during this low level of exercise.[6] Patient medications were not modified between invasive and non-invasive studies.

\section{Statistical analysis}

All quantitative data are expressed as medians and interquartile ranges, and qualitative data are expressed as numbers and percentages. The patients were classified according to LVEDP: group 1 was normal LVEDP at rest and during exercise; group 2 was normal LVEDP at rest and abnormal LVEDP during exercise; and group 3 was abnormal LVEDP both at rest and 
during exercise. The data were compared using the Fisher and Kruskal-Wallis exact tests. The Wilcoxon signed rank test was used for paired data analysis.

Correlations were evaluated using the Pearson test. To detect a correlation $>0.4$ between

LVEDP and echocardiography parameters with $90 \%$ power and a 2 -sided alpha level of 0.05 , a sample size of 60 patients was calculated. Receiver-operator characteristics (ROC) curves were plotted to assess E/e' to predict exercise LVEDP > $16 \mathrm{mmHg}$. The analyses were performed in the overall population and in subgroups of patients with or without apparent CD. Intraobserver and interobserver variabilities for the measurement of E/e' ratio at rest and during exercise were assessed in a subset of 10 patients. The coefficient of variation and intraclass correlation coefficient were determined and presented in supplemental table 1. MedCalc Statistical Software version 12.7.7 (MedCalc Software, Belgium) was used for the calculations. A p $<0.05$ indicated statistical significance.

\section{RESULTS}

\section{Population characteristics}

The baseline characteristics of the patients are presented in Table 1. The patients' median age was 63.5 years. Thirty-eight (63\%) patients had hypertension and $16(27 \%)$ had diabetes. Thirteen $(22 \%)$ patients had coronary stenosis $>50 \%$; however, none of these patients had a stenosis that required a percutaneous intervention. Among these patients, we observed no functional ischemia based on fractional flow reserve $(n=6)$, stenosis of a small artery with a diameter $<2 \mathrm{~mm}(\mathrm{n}=6)$ and a right coronary artery occlusion without significant stenosis on other arteries $(n=1)$. No patient had a history of congestive HF.

\section{Invasive hemodynamic measurements}

The invasive hemodynamic data are presented in Table 2. LVEDP at rest and in at least 1 exercise level were properly recorded in all of the patients. Two patients stopped the protocol 
after the first level of exercise. In 2 other patients, the LV pressure curve could not be properly analyzed at one of the two exercise stages.

LVEDP was normal in $46(77 \%)$ patients at rest. In $12(20 \%)$ of these patients, LVEDP remained normal during exercise (group 1), and in 34 (57\%) patients, it became elevated (group 2). The remaining 14 (23\%) patients had elevated LVEDP at rest and during exercise (group 3). Most of the change in LVEDP occurred within the first 3 minutes of exercise at a very low-level workload (Figure 1), $82 \%$ of the patients classified in group 2 had abnormal LVEDP since the first exercise level.

NT-pro BNP level was significantly higher in group 3 compared to group 1 and to group 2 respectively; however, NT-pro BNP levels in group 1 and group 2 were similar (Table 1). Twenty-four (40\%) patients experienced a dyspnea during low level exercise, and all of these patients had an abnormal LVEDP at rest and/or during exercise (Table 2).

\section{Echocardiography}

The median time between echocardiography and catheterization was $4 \mathrm{~h} 36 \mathrm{~min}$ [3h05min- $8 \mathrm{~h}$ ]. The ultrasound measurements are reported in Table 3.

\section{E/e' ratio}

$\mathrm{E}$ and $\mathrm{A}$ waves were fused in 4 patients at $25 \mathrm{Watts}$ and in 8 patients at 50 Watts.

In whole population, there was a correlation between LVEDP and septal E/e' at rest $(\mathrm{r}=0.28)$ and during exercise $(\mathrm{r}=0.34)$. Lateral E/e' was associated with LVEDP at 25 Watts of exercise $(\mathrm{r}=0.27)$. However, lateral E/e' was not linked to LVEDP at rest or at 50 Watts of exercise (supplemental figure). Compared with septal E/e', the E/average e' ratio had a worse correlation with LVEDP (Table 4).

Although, septal E/e' ratio at rest was similar between group 1 and group 2; exercise septal E/e' was higher in group 2 compared to group 1 since the first exercise level (Table 3). 
The ROC curve analysis for prediction of abnormal LVEDP from E/e' ratios showed that Septal E/e' at 25 Watts with an area under the curve (AUC) of 0.79 had the best diagnostic value (Figure 2). The optimal septal E/e' at 25 Watt threshold $\geq 8$ had a sensitivity of $71 \%$ and a specificity of $83 \%$ for predicting abnormal LVEDP.

\section{Performance of E/e' in patients with and without apparent CD}

Because E/e' ratio has been reported as a non-optimal index of LVFP in patients without apparent heart disease,[14-16] the population was divided into patients with $(n=26)$ and without $(n=34)$ apparent $C D$. The both groups had similar demographic and hemodynamic characteristics (supplemental table 2). In particular, the prevalence of abnormal LVEDP only during exercise $(\mathrm{p}=0.61)$ and the median time between echocardiography and catheterization $(\mathrm{p}=0.96)$ were similar in both groups.

Compared with the whole population, Doppler-derived parameters were better linked to LVEDP in patients with apparent CD. The best observed correlation was between septal E/e' and LVEDP at 25 Watts of exercise $(r=0.59, \mathrm{p}=0.002)$. In contrast, no significant correlation was observed between E/e' and LVEDP in patients without CD (supplemental table 3). In patients with $\mathrm{CD}$, the ROC curves analysis for prediction of abnormal LVEDP showed that septal E/e' at 25 Watts had the best diagnostic value (AUC=0.96). The optimal septal E/e' at 25 Watts $\geq 8$ had a sensitivity of $90 \%$ and a specificity of $100 \%$. In patients without $C D$, the E/e' ratios had no significant diagnostic value (Figure 3). 


\section{DISCUSSION}

The results of the study can be summarized as follows. First, we confirmed that exercise induced abnormal LVEDP in a number of patients with normal LVEDP at rest and that most of the changes in LVEDP occurred at a very low-level workload. Second, we observed a correlation between LVEDP and septal E/e' at rest and during exercise; however, lateral E/e' and E/average e' ratio had a worse correlation with LVEDP. Finally, we found that septal E/e' at 25 Watts of exercise was valuable for predicting abnormal exercise LVEDP. However, in subgroup analysis, although exercise septal E/e' has a very good diagnostic performance in patients with apparent $C D$, this parameter had no significant diagnostic value in the subgroup of patients with apparently normal LV morphology and no history of coronary artery disease.

\section{Invasive hemodynamics}

While cardiac dysfunction is readily apparent when the LVEF is reduced, the diagnosis of HF is not straightforward when LVEF is preserved.[6] Recent data indicate that the early stage of HFpEF, which is characterized by exercise-induced LVFP elevation despite normal resting pressures, represents a pathological entity linked to symptoms and long-term survival.[8] The invasive assessment of LVFP at peak exercise is feasible; $[6,8]$ however, this time-consuming approach is not optimal for routine clinical use and limits its dissemination. As we reported in our study and as observed previously,[6] the abnormal increase in LVFP with exercise is nonlinear, with most change occurring during the first level of exercise. Thus, the LVFP achieved at the first level of exercise could help diagnose an early stage of HFpEF in clinical practice.[7]

\section{E/e’ ratio}

The value of Doppler echocardiography to estimate invasively measured exercise LVFP was previously reported.[10] However, the use of E/e' ratio at rest for estimating LVFP was 
recently challenged [27] and validation data on exercise E/e' in patients with preserved LVEF are limited. In fact, of the 37 patients included in the validation study of exercise E/e' compared to direct invasive measures of LV diastolic pressure, six (16\%) had LVEF <45\%.[10] Moreover, using pulmonary capillary wedge pressure (PCWP) as reference method, two smaller studies including 12 and 22 patients respectively, reported conflicting results. $[11,12]$

For the non-invasive estimation of LVFP at rest, current guidelines encourage the use the ratio between the preload-dependent transmitral E velocity and e' velocity, which is considered relatively load independent.[16, 28] However, preload affects e' in ventricles with normal relaxation,[29] and E/e' has lower accuracy in patients without apparent CD because e' itself is altered by volume shifts.[14, 15] Consistently in the guidelines, it is stated that E/e' ratio should not be used to assess LVFP in subjects with likely normal LV relaxation as defined by no history of heart disease along with normal cardiac structure and function.[16, 28] This physiological fact may partially explain the conflicting results in previously reported studies investigated E/e' for exercise LVFP estimation.[10-12] In the former study showing the reliability of E/e' to identify patients with elevated exercise LVFP, the prevalence of coronary artery stenosis was high (75\%).[10] In another study reporting conflicting results, patients with coronary artery disease were excluded.[12] Finally, another study excluding patients with coronary stenosis showed that E/e' was not valuable to estimate PCWP variation in patients with preserved LVEF subjected to preload manipulation.[30] Using a direct sampling of LV cavity during left heart catheterization as reference method, our study is the largest prospective study aimed to investigate exercise E/e' in patients with preserved LVEF. The relatively large and carefully phenotyped population included allowed a subgroup analysis of patients with and without apparent CD. We found that exercise E/e' had a mild diagnostic value of abnormal LVEDP in the whole population. However, although E/e' 
had no diagnostic value in patients without $\mathrm{CD}$, this index had a good value to predict abnormal LVEDP in patients with apparent CD. Our data further indicate that E/e' should not be used for the assessment of LVFP in patients with preserved LVEF and without apparent CD.[16] To choose the appropriate ultrasound approach, our findings suggest the collection of patient clinical history and the assessment of LV morphology as the first step of the noninvasive estimation of exercise LVFP. As reported previously, we observed that latent HF could be unmasked during exercise in high risk patients with apparently normal LV structure and function at rest.[6,13] The best non-invasive approach of exercise LVFP in patients without apparent LV structural abnormality and/or history of coronary artery disease remains to be investigated.

We found that septal E/e' had better accuracy compared with lateral E/e' for the diagnosis of exercise LVEDP >16 mmHg. In previously reported studies on the same field, lateral E/e' was not investigated.[10-12] The septal side of the mitral annulus, in contrast to the lateral side, moves in a direction more parallel to the ultrasound beam and is less affected by the translational movement of the heart.

\section{Clinical implications}

The risk factors of HFpEF, especially age, hypertension and diabetes, are also recognized risk factors of coronary stenosis.[2] Moreover, the symptoms of coronary diseases are not specific and might also be suggestive of HFpEF.[2] In our study, 34 (57\%) of the patients with normal or subnormal coronary arteries and normal LVEDP at rest were diagnosed as having abnormal exercise LVEDP. These data indicate that the stress protocol used in our study, which combined radial artery puncture and low level stress exercise, could be clinically relevant in patients who were originally referred for a coronary angiography in whom no coronary artery 
lesion explains their symptoms and LVEDP is normal at rest. However, the efficiency of this diagnostic strategy should be validated in larger populations.

Concerning non-invasive diagnosis of abnormal exercise LVFP, our data indicate that exercise echocardiography at very low workload helps diagnose early stage HFpEF. This approach is suitable for routine clinical use. Compared to E/e' evaluation at peak exercise, low level workload E/e' could be combined to the resting ultrasound evaluation in selected population at high risk. This approach could be also easily integrated in current stress echocardiography protocols designed to avoid LV ischemia. Moreover, the uncommon rate of complete E and A merging at low level exercise facilitates Doppler analysis.[19, 26] Exercise septal E/e' appears to be superior to lateral and E/ average e' ratio. Finally, E/e' appears to be reliable only in patients with apparent $\mathrm{CD}$ and should not be used for the assessment of exercise LVFP in patients with normal LV morphology and no history of coronary artery disease.

\section{Study limitations}

We included a relatively small population of patients. However, the sample size was larger compared with prior reports that investigated the ultrasound for similar purpose.[10-12] The invasive and ultrasound acquisitions were not performed simultaneously. Performing simultaneous assessments may have enhanced the correlations between the two methods; however, it would be difficult to obtain good quality images in the catheterization laboratory, and this attempt would introduce another type of bias by excluding patients due to inadequate imaging. 


\section{CONCLUSION}

The early stage of HFpEF is characterized by exercise-induced LVFP elevation despite normal resting measurements. The abnormal increase in LVFP with exercise is nonlinear, with most change occurring during the first level of exercise. Low level exercise septal E/e' is valuable for predicting abnormal exercise LVEDP in patients with preserved LVEF and apparent CD. However, the non-invasive approach of LVEDP in patients with normal LV morphology and no history of coronary disease needs further investigations. The reliable noninvasive identification of early stages of HFpEF is the first step for clinical trials that evaluate specific treatment strategies targeting these high risk patients. 


\section{DISCLOSURES}

Dr. Laveau was supported by a grant from the French Federation of Cardiology. Dr. Komajda has performed consulting/advisory activities for Servier, Bristol-Myers Squibb, AstraZeneca, Menarini, Novartis, MSD, and Sanofi-Aventis. The other authors have no conflict of interest to declare related to the present study. 


\section{REFERENCES}

1. Steinberg BA, Zhao X, Heidenreich PA, et al (2012) Trends in patients hospitalized with heart failure and preserved left ventricular ejection fraction: prevalence, therapies, and outcomes. Circulation 126:65-75. doi: 10.1161/CIRCULATIONAHA.111.080770

2. Borlaug BA (2014) The pathophysiology of heart failure with preserved ejection fraction. Nat Rev Cardiol 11:507-515. doi: 10.1038/nrcardio.2014.83

3. Meinertz T, Diegeler A, Stiller B, et al (2015) German Heart Report 2013. Clin Res Cardiol Off J Ger Card Soc 104:112-123. doi: 10.1007/s00392-014-0799-7

4. von Scheidt W, Zugck C, Pauschinger M, et al (2014) Characteristics, management modalities and outcome in chronic systolic heart failure patients treated in tertiary care centers: results from the EVIdence based TreAtment in Heart Failure (EVITA-HF) registry. Clin Res Cardiol Off J Ger Card Soc 103:1006-1014. doi: 10.1007/s00392-0140743-x

5. Kasner M, Sinning D, Burkhoff D, Tschöpe C (2015) Diastolic pressure-volume quotient (DPVQ) as a novel echocardiographic index for estimation of LV stiffness in HFpEF. Clin Res Cardiol Off J Ger Card Soc 104:955-963. doi: 10.1007/s00392-015$0863-\mathrm{y}$

6. Borlaug BA, Nishimura RA, Sorajja P, et al (2010) Exercise Hemodynamics Enhance Diagnosis of Early Heart Failure With Preserved Ejection Fraction. Circ Heart Fail 3:588-595. doi: 10.1161/CIRCHEARTFAILURE.109.930701

7. Borlaug BA (2014) Exercise haemodynamics and outcome in patients with dyspnoea. Eur Heart J 35:3085-3087. doi: 10.1093/eurheartj/ehu350

8. Dorfs S, Zeh W, Hochholzer W, et al (2014) Pulmonary capillary wedge pressure during exercise and long-term mortality in patients with suspected heart failure with preserved ejection fraction. Eur Heart J 35:3103-3112. doi: 10.1093/eurheartj/ehu315

9. Ha J-W, Oh JK, Pellikka PA, et al (2005) Diastolic stress echocardiography: A novel noninvasive diagnostic test for diastolic dysfunction using supine bicycle exercise Doppler echocardiography. J Am Soc Echocardiogr 18:63-68. doi: 10.1016/j.echo.2004.08.033

10. Burgess MI, Jenkins C, Sharman JE, Marwick TH (2006) Diastolic Stress Echocardiography: Hemodynamic Validation and Clinical Significance of Estimation of Ventricular Filling Pressure With Exercise. J Am Coll Cardiol 47:1891-1900. doi: 10.1016/j.jacc.2006.02.042

11. Talreja DR, Nishimura RA, Oh JK (2007) Estimation of Left Ventricular Filling Pressure with Exercise by Doppler Echocardiography in Patients with Normal Systolic Function: A Simultaneous Echocardiographic-Cardiac Catheterization Study. J Am Soc Echocardiogr 20:477-479. doi: 10.1016/j.echo.2006.10.005 
12. Maeder MT, Thompson BR, Brunner-La Rocca H-P, Kaye DM (2010) Hemodynamic basis of exercise limitation in patients with heart failure and normal ejection fraction. $\mathrm{J}$ Am Coll Cardiol 56:855-863. doi: 10.1016/j.jacc.2010.04.040

13. Tan YT, Wenzelburger F, Lee E, et al (2010) Abnormal left ventricular function occurs on exercise in well-treated hypertensive subjects with normal resting echocardiography. Heart Br Card Soc 96:948-955. doi: 10.1136/hrt.2009.185181

14. Firstenberg MS, Levine BD, Garcia MJ, et al (2000) Relationship of echocardiographic indices to pulmonary capillary wedge pressures in healthy volunteers. J Am Coll Cardiol 36:1664-1669.

15. Dokainish H, Zoghbi WA, Lakkis NM, et al (2004) Optimal noninvasive assessment of left ventricular filling pressures: a comparison of tissue Doppler echocardiography and B-type natriuretic peptide in patients with pulmonary artery catheters. Circulation 109:2432-2439. doi: 10.1161/01.CIR.0000127882.58426.7A

16. Nagueh SF, Appleton CP, Gillebert TC, et al (2009) Recommendations for the evaluation of left ventricular diastolic function by echocardiography. Eur J Echocardiogr J Work Group Echocardiogr Eur Soc Cardiol 10:165-193. doi: 10.1093/ejechocard/jep007

17. Oh JK, Kane GC (2014) Diastolic stress echocardiography: the time has come for its integration into clinical practice. J Am Soc Echocardiogr Off Publ Am Soc Echocardiogr 27:1060-1063. doi: 10.1016/j.echo.2014.08.013

18. Hammoudi N, Achkar M, Isnard R (2015) Exercise E/e' for the assessment of left ventricular filling pressures: with caution in clinical practice? J Am Soc Echocardiogr Off Publ Am Soc Echocardiogr 28:376-377. doi: 10.1016/j.echo.2014.11.001

19. Erdei T, Smiseth OA, Marino P, Fraser AG (2014) A systematic review of diastolic stress tests in heart failure with preserved ejection fraction, with proposals from the EUFP7 MEDIA study group. Eur J Heart Fail 16:1345-1361. doi: 10.1002/ejhf.184

20. Lang RM, Badano LP, Mor-Avi V, et al (2015) Recommendations for cardiac chamber quantification by echocardiography in adults: an update from the American Society of Echocardiography and the European Association of Cardiovascular Imaging. Eur Heart J Cardiovasc Imaging 16:233-270. doi: 10.1093/ehjci/jev014

21. Penicka M, Bartunek J, Trakalova H, et al (2010) Heart Failure With Preserved Ejection Fraction in Outpatients With Unexplained Dyspnea. J Am Coll Cardiol 55:1701-1710. doi: 10.1016/j.jacc.2009.11.076

22. Borlaug BA, Paulus WJ (2011) Heart failure with preserved ejection fraction: pathophysiology, diagnosis, and treatment. Eur Heart J 32:670-679. doi: 10.1093/eurheartj/ehq426

23. Buss SJ, Krautz B, Schnackenburg B, et al (2014) Classification of diastolic function with phase-contrast cardiac magnetic resonance imaging: validation with echocardiography and age-related reference values. Clin Res Cardiol Off J Ger Card Soc 103:441-450. doi: 10.1007/s00392-014-0669-3 
24. Nagueh SF, Mikati I, Kopelen HA, et al (1998) Doppler estimation of left ventricular filling pressure in sinus tachycardia. A new application of tissue doppler imaging. Circulation 98:1644-1650.

25. Voss F, Schueler M, Lauterbach M, et al (2016) Safety of symptom-limited exercise testing in a big cohort of a modern ICD population. Clin Res Cardiol Off J Ger Card Soc 105:53-58. doi: 10.1007/s00392-015-0885-5

26. Hammoudi N, Achkar M, Laveau F, et al (2014) Left atrial volume predicts abnormal exercise left ventricular filling pressure. Eur J Heart Fail 16:1089-1095. doi: 10.1002/ejhf.131

27. Santos M, Rivero J, McCullough SD, et al (2015) E/e' Ratio in Patients With Unexplained Dyspnea: Lack of Accuracy in Estimating Left Ventricular Filling Pressure. Circ Heart Fail 8:749-756. doi: 10.1161/CIRCHEARTFAILURE.115.002161

28. Nagueh SF, Smiseth OA, Appleton CP, et al (2016) Recommendations for the Evaluation of Left Ventricular Diastolic Function by Echocardiography: An Update from the American Society of Echocardiography and the European Association of Cardiovascular Imaging. J Am Soc Echocardiogr Off Publ Am Soc Echocardiogr 29:277-314. doi: 10.1016/j.echo.2016.01.011

29. Firstenberg MS, Greenberg NL, Main ML, et al (2001) Determinants of diastolic myocardial tissue Doppler velocities: influences of relaxation and preload. J Appl Physiol Bethesda Md 1985 90:299-307.

30. Bhella PS, Pacini EL, Prasad A, et al (2011) Echocardiographic indices do not reliably track changes in left-sided filling pressure in healthy subjects or patients with heart failure with preserved ejection fraction. Circ Cardiovasc Imaging 4:482-489. doi: 10.1161/CIRCIMAGING.110.960575 


\section{FIGURE LEGENDS}

Figure 1. LVEDP at rest and during exercise in the 3 groups of patients. Most of the changes in LVEDP occurred during the first level of exercise.

Group 1, normal LVEDP; Group 2, abnormal LVEDP only during exercise; Group 3, abnormal LVEDP at rest and during exercise; LVEDP, left ventricular end diastolic pressure. Within group analyses: ${ }^{*} \mathrm{p}<0.05$ versus at rest; $\uparrow \mathrm{p}<0.0001$ versus at rest; $\$ \mathrm{p}<0.0001$ versus at 25Watts.

Figure 2. Receiver-operator characteristic curves for the prediction of exercise LVEDP >16 $\mathrm{mmHg}$ in the whole study population using septal (A) and lateral (B) E/e' ratios at rest and during exercise.

AUC, area under the curve; LVEDP, left ventricular end diastolic pressure.

Figure 3. Typical low level exercise echocardiography findings in two patients with exercise induced abnormal LVEDP. While exercise septal E/e' increases in the patient with apparent $\mathrm{CD}$, this parameter was not modified in the patient without $\mathrm{CD}$.

$\mathrm{CD}$, patient with apparent cardiac disease (ie, coronary artery disease or echocardiographic evidence of left ventricular structural abnormality); E/e', the ratio of early diastolic transmitral velocity to tissue velocity; LVEDP, left ventricular end diastolic pressure. 
TABLES

Table 1: Clinical characteristics of the study population.

\begin{tabular}{|lcccc|c|}
\hline Variables & All patients & Group 1 & Group 2 & Group 3 & p \\
& $(\mathrm{n}=60)$ & $(\mathrm{n}=12)$ & $(\mathrm{n}=34)$ & $(\mathrm{n}=14)$ & \\
\hline Demographics & & & & & \\
Age (years) & $63.5[54.6-70.3]$ & $59.3[48.4-67.2]$ & $64.8[55.2-73.4]$ & $62.6[55.2-67.9]$ & 0.20 \\
Male gender & $46(77)$ & $11(92)$ & $26(77)$ & $9(64)$ & 0.31 \\
Body Mass index, kg/m² & $26.4[23.9-28.5]$ & $27.5[25.1-29.9]$ & $25.4[23.4-27.4]$ & $27.7[23.4-29.4]$ & 0.09 \\
Prior PCI & $14(23)$ & $3(25)$ & $8(24)$ & $3(21)$ & 1.0 \\
Coronary stenosis $>50 \%$ & $13(22)$ & $3(25)$ & $8(23.5)$ & $2(14)$ & 0.83 \\
Hypertension & $38(63)$ & $9(75)$ & $18(53)$ & $11(79)$ & 0.18 \\
Diabetes & $16(27)$ & $3(25)$ & $10(29)$ & $3(21)$ & 0.92 \\
Smoking history & $31(52)$ & $5(42)$ & $21(62)$ & $5(36)$ & 0.23 \\
Drug therapy & & & & & \\
$\beta$-blockers & $29(48)$ & $4(33)$ & $17(50)$ & $8(57)$ & 0.50 \\
ACE or ARB & $31(52)$ & $7(58)$ & $16(47)$ & $8(57)$ & 0.82 \\
Calcium Chanel Blockers & $14(23)$ & $4(33)$ & $9(26)$ & $1(7)$ & 0.22 \\
Loop diuretics & $1(1.5)$ & $0(0)$ & $1(3)$ & $0(0)$ & 1.0 \\
Biology & & & & & \\
NT-proBNP $(\mathrm{pg} / \mathrm{mL})$ & $55[28-110]^{*}$ & $34[18-87]$ & $48[27-97]^{\dagger}$ & $118[100-372]^{\ddagger} \$$ & 0.002 \\
Hemoglobin $(\mathrm{g} / \mathrm{dL})$ & $14.5[13.3-15]$ & $14.9[14.3-15.5]$ & $14.2[13.2-14.9]$ & $14.5[13-14.8]$ & 0.16 \\
Creatinine level $(\mu \mathrm{mol} / \mathrm{L})$ & $80[73.5-97.5]$ & $79[73.5-88]$ & $81.5[73-101]$ & $79.5[74-102]$ & 0.93 \\
\hline
\end{tabular}

Data are expressed as median and interquartile range or number $(\%)$.

$* \mathrm{n}=57,{ }^{\dagger} \mathrm{n}=33,{ }^{*} \mathrm{n}=12$

$\S \mathrm{p}<0.05$ compared to group 1 and to group 2.

ACE, Angiotensin converting enzyme inhibitor; ARB, Angiotensin receptor blocker; Group 1, normal LVEDP;

Group 2, abnormal LVEDP only during exercise; Group 3, abnormal LVEDP at rest; LVEDP, left ventricular end diastolic pressure; NT-proBNP, N-terminal pro brain natriuretic peptide; PCI, percutaneous coronary intervention. 
Table 2: Invasive hemodynamic data.

\begin{tabular}{|c|c|c|c|c|c|}
\hline Variables & $\begin{array}{l}\text { All patients } \\
\qquad(\mathrm{n}=60)\end{array}$ & $\begin{array}{c}\text { Group } 1 \\
(n=12)\end{array}$ & $\begin{array}{c}\text { Group } 2 \\
(n=34)\end{array}$ & $\begin{array}{c}\text { Group } 3 \\
\quad(n=14)\end{array}$ & $\mathbf{p}$ \\
\hline \multicolumn{6}{|c|}{ Symptoms during exercise } \\
\hline Dyspnea & $24(40)$ & $0(0)$ & $16(47)$ & $8(57)$ & 0.002 \\
\hline Lower extremity fatigue & $2(3)$ & $1(8)$ & $0(0)$ & $1(7)$ & 0.18 \\
\hline \multicolumn{6}{|l|}{ Heart rate (beats/min) } \\
\hline at rest & $72[65-80]$ & $72[65-76]$ & 75 [65-80] & $71[60-78]$ & 0.54 \\
\hline at $25 \mathrm{~W}$ exercise & $95[88-100]^{*}$ & $91[85-99]$ & $99[90-100]$ & $93[82-100]$ & 0.33 \\
\hline at $50 \mathrm{~W}$ exercise & $104[100-110]^{\dagger}$ & $102[96-108]^{*}$ & $105[100-113] \S$ & $103[95-110]^{\|}$ & 0.53 \\
\hline \multicolumn{6}{|c|}{ LV Systolic Pressure (mmHg) } \\
\hline at rest & $128[117-142]$ & 124 [110-127] & $130[117-146] \mathbb{I}$ & 138 [124-151]凹 & 0.01 \\
\hline at $25 \mathrm{~W}$ exercise & $160[142-175]^{*}$ & $146[131-156]$ & $165[142-180] \S \llbracket$ & 169 [154-175]⿻ & 0.009 \\
\hline at $50 \mathrm{~W}$ exercise & $164[153-187]^{\dagger}$ & $158[141-163]^{\sharp}$ & $174[153-189] \S \llbracket$ & $169[157-184]^{\|}$ & 0.02 \\
\hline \multicolumn{6}{|l|}{ LVEDP (mmHg) } \\
\hline at rest & $13.5[10-16]$ & $10[6-12]$ & $12[10-14]$ & $20[18-22]$ & $<0.0001$ \\
\hline at $25 \mathrm{~W}$ exercise & $22[15-27]^{*}$ & 13 [12-14.5] & $22[20-25] \S$ & $28.5[25-30]$ & $<0.0001$ \\
\hline at $50 \mathrm{~W}$ exercise & $25[19.5-30]^{\dagger}$ & $12[10.5-15]^{\ddagger}$ & $25[20-30] \S$ & $30[28-34]^{\|}$ & $<0.0001$ \\
\hline
\end{tabular}

Data are expressed as median and interquartile range.

* $\mathrm{n}=59, \dagger \mathrm{n}=57,+\mathrm{n}=11, \S \mathrm{n}=33, \| \mathrm{n}=13, \uparrow \mathrm{p}<0.05$ compared to group 1

LV, left ventricular; LVEDP, left ventricular end diastolic pressure 
Table 3: Echocardiographic data.

\begin{tabular}{|c|c|c|c|c|c|}
\hline Variables & $\begin{array}{l}\text { All patients } \\
\qquad(\mathrm{n}=60)\end{array}$ & $\begin{array}{c}\text { Group } 1 \\
(n=12)\end{array}$ & $\begin{array}{c}\text { Group } 2 \\
(n=34)\end{array}$ & $\begin{array}{c}\text { Group } 3 \\
(\mathrm{n}=14)\end{array}$ & $\mathbf{p}$ \\
\hline \multicolumn{6}{|l|}{ At rest } \\
\hline $\operatorname{LVEF}(\%)$ & $66[60-71]$ & 64 [59-69] & 66 [60-72] & 63 [59-71] & 0.29 \\
\hline LVEDVi (ml/m²) & $55.2[44.1-62.5]$ & $57.1[50.1-63.1]$ & $49.9[42.7-62.3]$ & $56.7[52.3-62.1]$ & 0.53 \\
\hline LVMi $\left(\mathrm{g} / \mathrm{m}^{2}\right)$ & 91 [82-104] & 95 [88-106] & 87 [77-102] & 95 [85-109] & 0.29 \\
\hline $\mathrm{LAVi}\left(\mathrm{ml} / \mathrm{m}^{2}\right)$ & 33.6 [28-41.2] & 31.3 [26-33.8] & $35.1[27.9-41.4]$ & 35.6 [28.9-43.7] & 0.21 \\
\hline $\mathrm{E}(\mathrm{cm} / \mathrm{s})$ & $72[62-85]$ & 73 [57-81] & $70[61-84]$ & 76 [69-98] & 0.11 \\
\hline $\mathrm{A}(\mathrm{cm} / \mathrm{s})$ & $76[68-88]$ & $72[60-81]$ & $78[68-90]$ & 77 [71-88] & 0.40 \\
\hline $\mathrm{E} / \mathrm{A}$ ratio & $0.97[0.74-1.16]$ & $0.89[0.72-1.28]$ & $0.95[0.72-1.13]$ & $1.07[0.87-1.36]$ & 0.38 \\
\hline Deceleration time (ms) & 164 [145-194] & 165 [147-170] & 169 [154-206] & 157 [123-186] & 0.33 \\
\hline Septal e' $(\mathrm{cm} / \mathrm{s})$ & 9 [7-10.5] & $9.7[8.5-10.9]$ & 9 [7-10.7] & 8.9 [7-9.7] & 0.45 \\
\hline Lateral e' $(\mathrm{cm} / \mathrm{s})$ & $11[8.9-13.3]$ & $10.5[9.3-13]$ & $11.2[9-13.3]$ & $10.9[8-12.3]$ & 0.86 \\
\hline Septal E/e' & $8.1[6.6-10.6]$ & $7.2[6.7-8.1]$ & $7.9[6.5-10.4]$ & $10.2[8.5-11.3] \#$ & 0.02 \\
\hline Lateral E/e' & $6.9[5.8-8]$ & $6.4[5.6-7.3]$ & $6.7[5.5-7.5]$ & 8.2 [6.3-8.9] & 0.06 \\
\hline E/average e' & $7.4[6.1-8.9]$ & $6.8[6.0-7.5]$ & $7.1[5.9-8.8]$ & 8.8 [7.4-9.7]\# \#†† & 0.03 \\
\hline $\mathrm{TRV}(\mathrm{m} / \mathrm{s})$ & $2.4[2.3-2.6]^{*}$ & $2.2[2.1-2.5]^{\dagger}$ & $2.4[2.3-2.6]^{\ddagger}$ & $2.3[2.3-2.5]^{\S}$ & 0.23 \\
\hline \multicolumn{6}{|l|}{ Exercise data } \\
\hline $\mathrm{E}$ at $25 \mathrm{~W}(\mathrm{~cm} / \mathrm{s})$ & 89 [75-101] & 77 [72-83] & 92 [77-103]\# & 101 [81-102]\# & 0.02 \\
\hline $\mathrm{E}$ at $50 \mathrm{~W}(\mathrm{~cm} / \mathrm{s})$ & $102[87-117]^{\|}$ & 87 [81-94] & $107[90-124]^{\mathbb{I}} \#$ & 109 [88-117]\# & 0.01 \\
\hline Septal e' at $25 \mathrm{~W}(\mathrm{~cm} / \mathrm{s})$ & $10.5[9.3-11.8]$ & $10.6[9.6-11.6]$ & $10.6[9.2-12.2]$ & $9.4[7.5-11.3]$ & 0.43 \\
\hline Septal e' at $50 \mathrm{~W}(\mathrm{~cm} / \mathrm{s})$ & $11.8[10.3-13.3]$ & $12.2[10.4-13.3]$ & $11.8[11-13.6]$ & $11[9-12.5]$ & 0.20 \\
\hline Lateral e' at $25 \mathrm{~W}(\mathrm{~cm} / \mathrm{s})$ & $12.3[10.6-14]$ & 11.5 [10.7-13.9] & $12.8[10.7-14.3]$ & $11.9[10-13.5]$ & 0.43 \\
\hline Lateral e' at $50 \mathrm{~W}(\mathrm{~cm} / \mathrm{s})$ & $14[12.2-16]$ & $12.9[12.1-14.8]$ & $14.7[12.1-16.4]^{\mathbb{I}}$ & $13.6[12.2-14.7]$ & 0.27 \\
\hline Septal E/e' at $25 \mathrm{~W}$ & 8.3 [7.3-9.9] & $7.3[6.7-7.6]$ & 8.6 [7.5-9.9]\# & 9.6 [8.1-11.6]\# & 0.004 \\
\hline Septal E/e' at $50 \mathrm{~W}$ & 8.7 [6.9-10.2]" & $7[6.4-9.2]$ & $8.4[7.2-10.4] \#^{\pi /}$ & 9.7 [8.6-11.5]\# & 0.04 \\
\hline Lateral E/e' at $25 \mathrm{~W}$ & $7.1[6.0-8.6]$ & $6.6[5.5-7.4]$ & $7.1[5.7-9]$ & $8.1[6.6-9.9]$ & 0.07 \\
\hline Lateral E/e' at $50 \mathrm{~W}$ & $7.3[5.8-8.9]]^{\|}$ & $6.4[5.4-8.2]$ & $7.2[5.7-8.9]^{\mathbb{I I}}$ & $8.3[6.1-9.1]$ & 0.28 \\
\hline E/average e' at $25 \mathrm{~W}$ & 7.6 [6.5-9.4] & 6.7 [6.4-7.5] & 7.9 [6.4-9.6]\# & 8.9 [7.5-11.0]\# & 0.02 \\
\hline E/average e' at $50 \mathrm{~W}$ & $8.1[6.2-9.1]^{\|}$ & $6.6[6.0-8.6]$ & $8.1[6.4-9.0]^{\mathbb{I I}}$ & 8.8 [7.4-10.5]\# & 0.11 \\
\hline
\end{tabular}

Data are expressed as median and interquartile range.

$* \mathrm{n}=37, \dagger \mathrm{n}=5, \ddagger \mathrm{n}=23, \S \mathrm{n}=9, \| \mathrm{n}=58, \uparrow \mathrm{n}=32, \# \mathrm{p}<0.05$ compared to group 1

A, late peak diastolic velocity of the mitral inflow; E, early peak diastolic velocity of the mitral inflow; e', early diastolic tissue velocity of mitral annulus; E/e', the ratio of early diastolic transmitral velocity to tissue velocity; LA, left atrial; LAVi, left atrial maximal volume index; LVEDVi: left ventricular end diastolic volume index; LVEF, left ventricular ejection fraction; LVMi: left ventricular mass index; TRV, tricuspid regurgitation velocity. 
Table 4: Univariate correlations of E/e' with LVEDP at rest and during exercise.

\begin{tabular}{|lllcc|}
\hline \multirow{2}{*}{ LVEDP at rest } & Variables & $\mathbf{n}$ & $\mathbf{r}$ & $\mathbf{p}$ \\
& Septal E/e' at rest & 60 & 0.28 & 0.03 \\
& Lateral E/e' at rest & 60 & 0.21 & 0.10 \\
& E/average e' & 60 & 0.26 & 0.04 \\
LVEDP at 25W & Septal E/e' at 25 Watts & 59 & 0.34 & 0.008 \\
& Lateral E/e' at 25 Watts & 59 & 0.27 & 0.04 \\
& E/average e' at 25 Watts & 59 & 0.31 & 0.02 \\
& Septal E/e' at 50 Watts & 55 & 0.34 & 0.01 \\
& Lateral E/e' at 50 Watts & 55 & 0.17 & 0.23 \\
& E/average e' at 50 Watts & 55 & 0.27 & 0.05 \\
\hline
\end{tabular}

E/e', the ratio of early diastolic transmitral velocity to tissue velocity; LVEDP, left ventricular end diastolic pressure. 


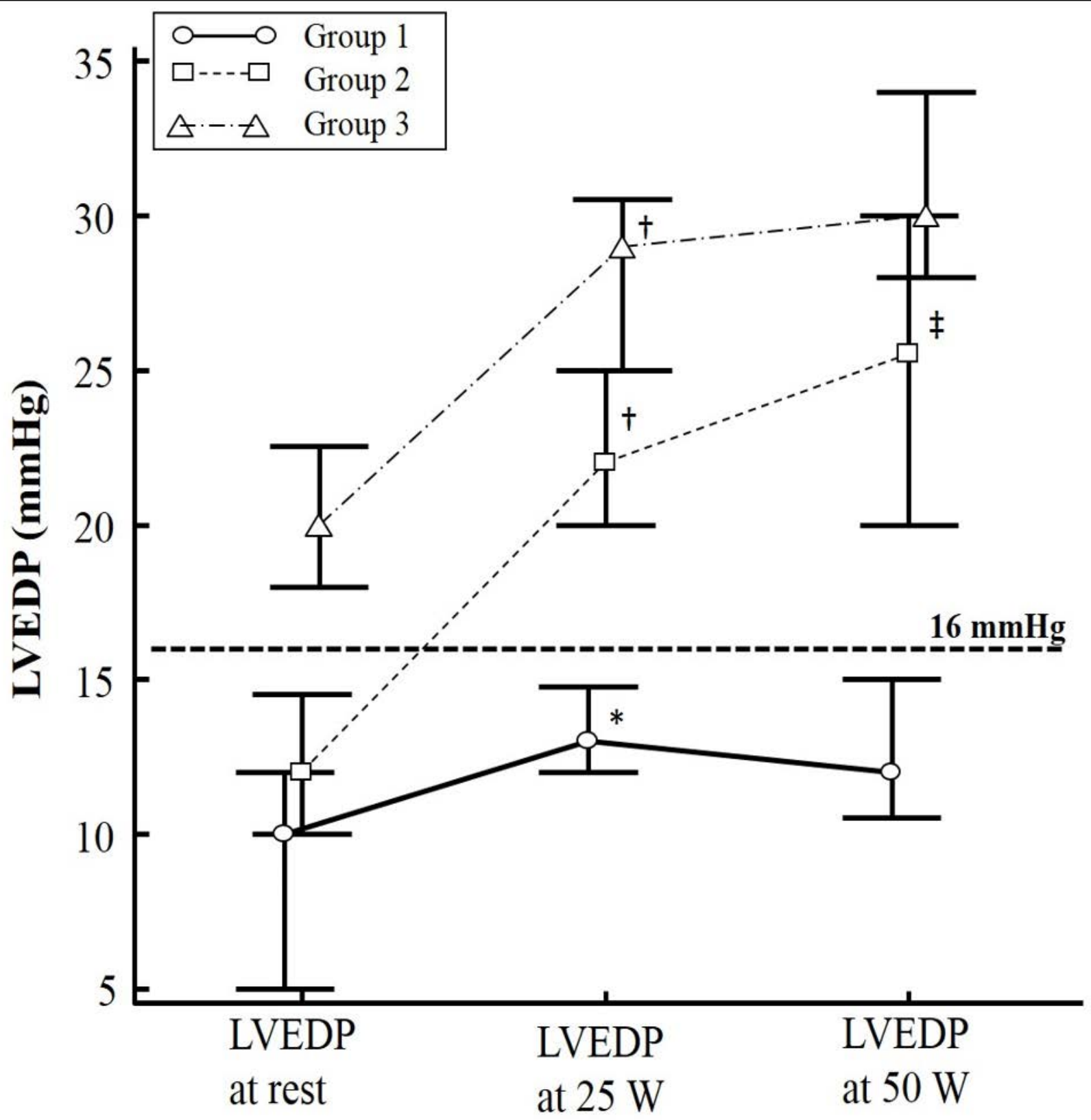



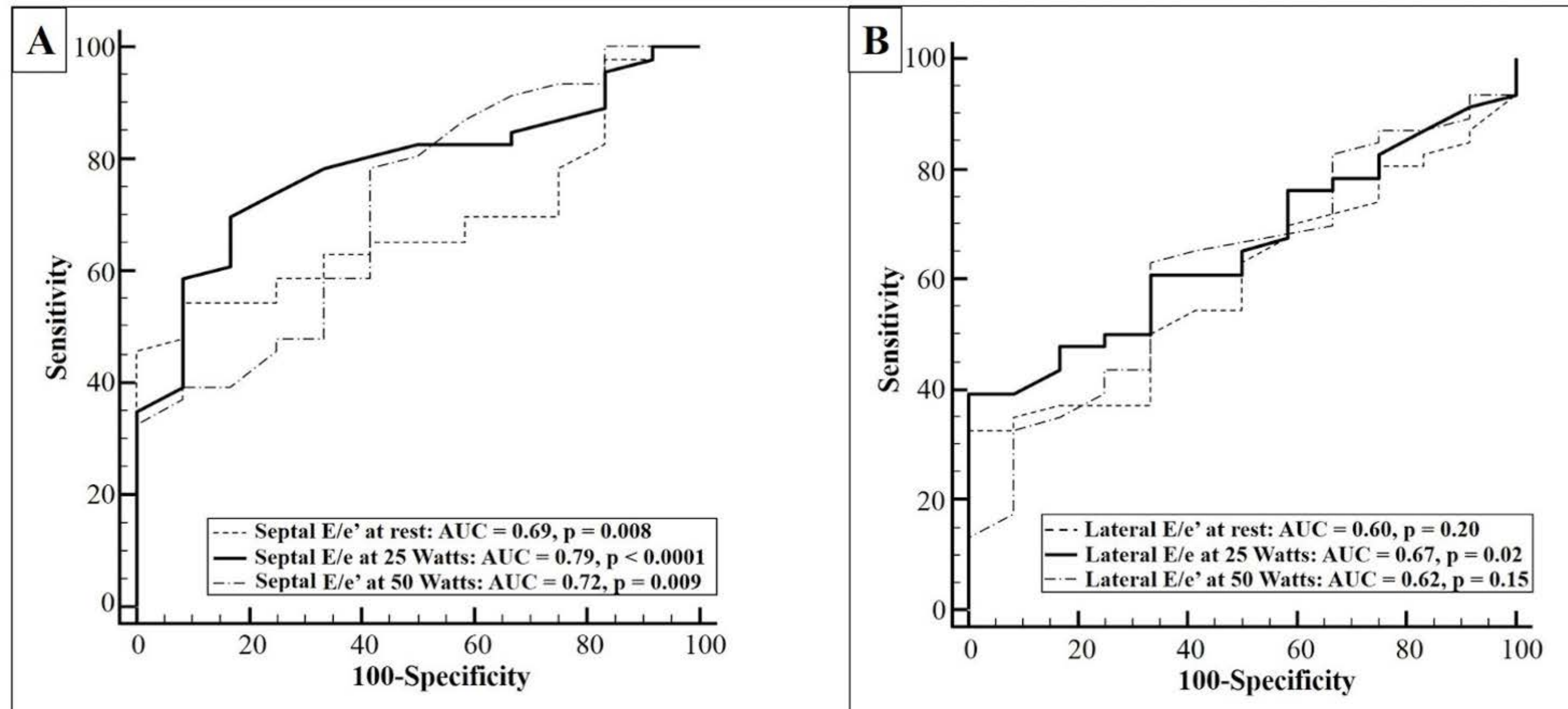
CD

At rest
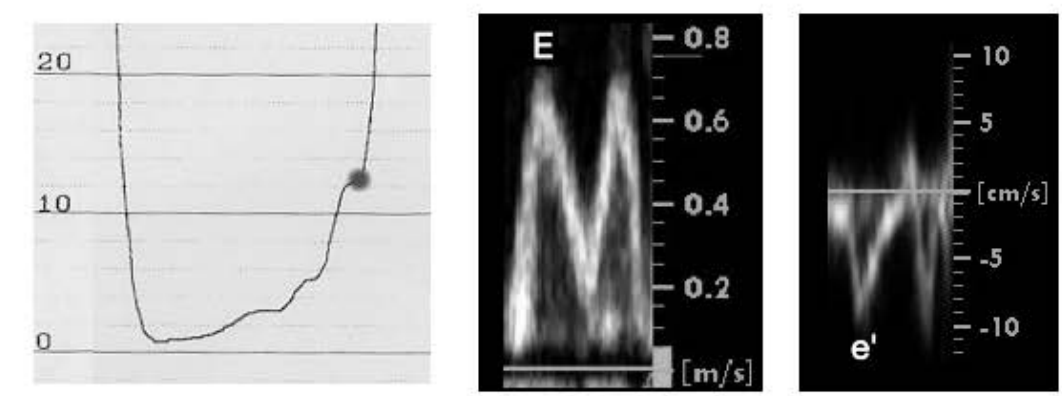

LVEDP $=12 \mathrm{mmHg}$

25 Watts

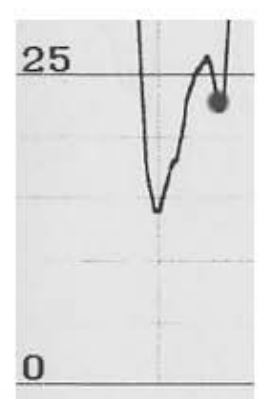

LVEDP $=23 \mathrm{mmHg}$
Septal $E / e^{\prime}=7.8$

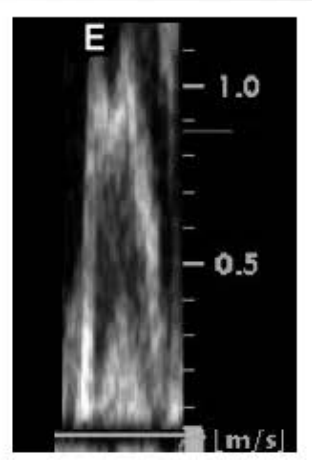

Septal E/e' $=10.7$

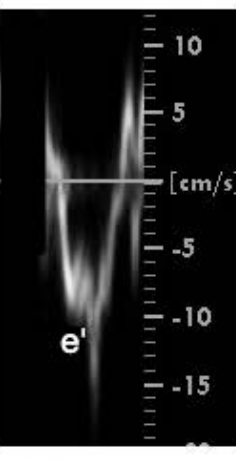

$-10$

$-5$

$-10$

$\overline{-}-15$

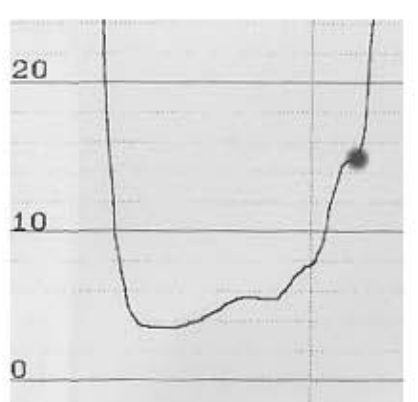

LVEDP $=15 \mathrm{mmHg}$

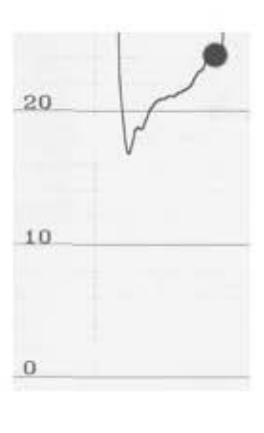

LVEDP $=24 \mathrm{mmHg}$

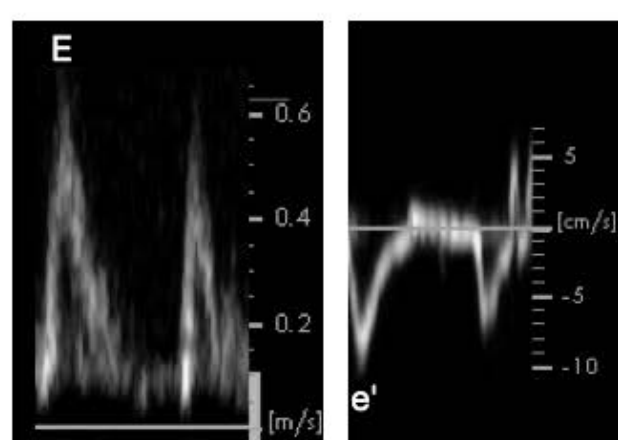

Septal $E / e^{\prime}=6$
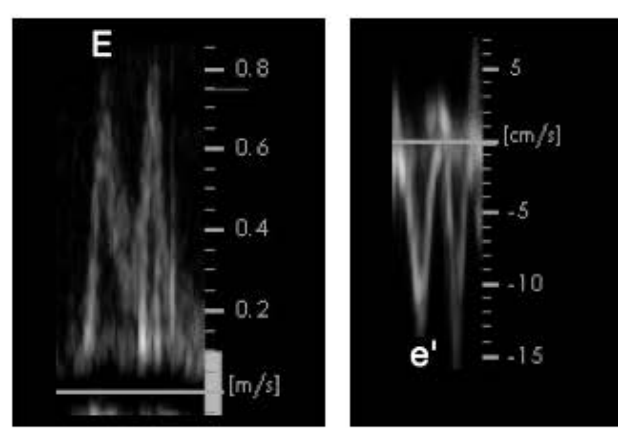

Septal E/e' $=6$ 